\title{
ECONOMÍA POLÍTICA, DESIGUALDAD \\ Y LIBERALISMO, 1750-1850
}

\section{POLITICAL ECONOMICS, INEQUALITY AND LIBERALISM, 1750-1850}

\author{
Joaquín Ocampo Suárez-Valdés \\ Universidad de Oviedo
}

SUMARIO: INTRODUCCIÓN. I. DEL MERCANTILISMO A LA ILUSTRACIÓN: RIESGOS MORALES Y POLÍTICOS DE LA DESIGUALDAD. 1.1. Mercantilismo: la secularización del debate sobre la pobreza. 1.2. Economía política e ilustración: la desigualdad como problema político. 1.3. Ilustración tardía: de la "felicidad pública" al "interés particular", 1788-1808. II. LAS CORTES DE CÁDIZ Y CONSAGRACIÓN POLÍTICA DE LA DESIGUALDAD, 1808-1814. III. LIBERALISMO, PROPIEDAD Y DESIGUALDAD, 1814-1830. 3.1. La economía política como ciencia neutral. 3.2. La economía política como ciencia social. 3.3. La desigualdad en el debate político-constitucional. IV. ECONOMÍA POLÍTICA Y "CUESTIÓN SOCIAL", 1833-1850. 4.1. Respuestas políticas a la desigualdad: de la "libertad y orden" a las soluciones heterodoxas. 4.2. Las respuestas desde la economía política: "eclecticismo" y filantropía liberal. CONCLUSIONES.

Resumen: La transición del Antiguo Régimen al liberalismo se dotará de una filosofia jurídica legitimadora que entronizará la propiedad como condición de acceso a la ciudadanía y a la participación política. La economía política tampoco faltará a la cita con la causa liberal: mercado, "interés particular" y "propiedad perfecta", se configurarán como nuevos antídotos frente a la desigualdad.

Abstract: The transition for the ancien régime towards Liberalism will be based upon a legitimizing legal philosophy which will set ownership as the primary condition granting access to citizenship and political participation. Political economics will also lend a hand to the liberal cause: market, 'private interest' and 'perfect ownership' will become the new antidotes against inequality.

Palabras clave: economía política, liberalismo, propiedad, desigualdad.

Key words: political economics, liberalism, ownership, inequality.

\section{INTRODUCCIÓN}

En la transición del Antiguo Régimen al liberalismo, la economía política puso todo su bagaje doctrinal al servicio de la causa liberal. "Felicidad pública", "interés particular" y "propiedad perfecta" se erigirán en garantes de la "mano invisible" del mercado. Este último, en tanto equilibrador óptimo de rentas, despojará a la desigualdad de consideraciones normativas para remitirla a la esfera positiva de la conducta individual. No obstante, frente al consenso dominante en la economía política, no faltarán voces críticas impugnadoras de la nueva filosofia. Tras 
un siglo de debates, ni la economía ni la política serán capaces de alcanzar soluciones de equilibrio para una población que se debatía entre la desintegración de la sociedad rural y un escenario urbano e industrial poco alentador. La desafección hacia la causa liberal por amplios sectores sociales será el resultado final de aquella incapacidad.

El análisis de la desigualdad económica —entendida como resultado de las diferentes condiciones de acceso a la propiedad y/o explotación de los recursos productivos - ha sido habitualmente abordado desde las perspectivas social, politica y de la "filosofia moral", poniendo énfasis en el pauperismo, los sistemas asistenciales o el alcance del derecho de propiedad, respectivamente ${ }^{1}$. En este artículo se ensayará una perspectiva nueva, la proporcionada por la economía política.

La transición del Antiguo Régimen al liberalismo se dotó de una filosofia jurídica legitimadora —iusnaturalismo, constitucionalismo liberal- que entronizará la propiedad como condición de acceso a la ciudadanía y a la participación política. Todo ello dentro de una construcción histórica que pretendía sustraerse al relativismo del devenir, que se presentaba "no como producto de una realidad mudable, sino como canon con el que medir la mutabilidad" ${ }^{2}$. La economía politica no faltará a la cita con el nuevo orden institucional.

\section{DEL MERCANTILISMO A LA ILUSTRACIÓN: RIESGOS MORALES Y POLÍTI- COS DE LA DESIGUALDAD}

\subsection{Mercantilismo: la secularización del debate sobre la pobreza}

Desde el siglo XV, el renacimiento urbano, la creciente monetización de la economía y una mayor movilidad social dieron visibilidad a una pobreza hasta entonces refugiada en los campos. La legislación sobre socorro a los pobres se hace más frecuente. Será en este contexto en el que se sitúe la reflexión escolástica sobre la conciliación entre los principios morales —comunidad primitiva de bienes-, derecho natural a la supervivencia, y realidad histórica - la apropiación particular de esos bienes reconocida por el derecho de gentes-. La solución se dará desde el paradigma de la ley natural: la propiedad, institucionalizada por el derecho de gentes, se considera un atributo del trabajo pero restringida en su disfrute a la conservación y cohesión del orden social.

La controversia sobre el socorro a los pobres, iniciada en 1545 con el debate Soto-Medina — que se prolongará hasta finales de siglo en las obras de Pérez Herrera y Juan de Mariana-, se polarizó entre quienes, asimilando pobreza a inestabilidad social, demandaban un tratamiento político de la misma ("policia de pobres") y aquellos otros que, equiparando el derecho de supervivencia al de propie-

1 Una sintesis, en Manuel Jesús González, El concepto de orden social en la historia del pensamiento económico, Real Academia de la Historia, Madrid, 2004; Nieves San Emeterio, Sobre la propiedad. El concepto de propiedad en la Edad Moderna, Tecnos, Madrid, 2005. Para una aproximación desde la perspectiva social, Manuel Esteban de Vega (ed.), "Pobreza, beneficencia y política social", Ayer, n. ${ }^{\circ}$ 25, 1997 y J. Álvarez Junco (ed.), Historia de la acción social pública en España. Beneficencia y previsión, Ministerio de Trabajo y Seguridad Social, Madrid, 1984.

2 Cfr. Paolo Grossi, La propiedad y las propiedades. Un análisis histórico, Cívitas, Madrid, 1992, pp. 31-34. Véase igualmente Clara Álvarez Alonso, "Las dos caras de Jano: propiedad y constitución en el primer liberalismo español”, en R. Robledo (eds.), Historia de la propiedad en España, siglos $X V-X X$, Universidad de Salamanca, 1999, págs. 297-327. 
dad, legitimaban un laissez-faire social atenuado por el sistema de caridad tradicional $^{3}$.

De la Reforma protestante a la "revolución científica" del Barroco se irán gestando cambios en la matriz epistemológica del tomismo: la "recta razón» escolástica dejará paso a la "razón científica" cartesiana y baconiana, y la ley natural normativa, a la analítica (Schumpeter). Keynes situaba en Locke y Hume la transición del imperativo moral al utilitario, el momento en que la libertad natural y los contratos entre particulares sustituian al primado del derecho divino.

El escenario económico español de los siglos XVI y XVII añadirá nuevos matices al citado debate. La inflación, la multiplicación de censos y juros, y la arribada de metales preciosos desplazan la atención de los teólogos y juristas de la Escuela de Salamanca hacia los temas monetarios: cohonestar acumulación de capital y moral católica — -Salvar almas»— será la prioridad analítica ${ }^{4}$. Por el contrario, para los arbitristas, la "gran consulta" promovida en 1618 por Felipe III para buscar salidas a una España "consumida y empeñada" será el punto de partida de una corriente que subordinará el tratamiento de la pobreza al de la "decadencia": en este caso, la prioridad será "salvar a España". Por esa vía, la reflexión económica se seculariza y abandona el terreno de la economía moral para instalarse en el de la economía aplicada 5 .

\title{
1.2. Economía política e Ilustración: la desigualdad como problema político
}

\author{
Por fortuna, se va haciendo moda en Europa atender al bien \\ público. Sin la riqueza del pueblo, jamás será sensible la fuerza \\ de un estado \\ (Campomanes, 1763)
}

La recepción del "mercantilismo liberal" inglés (aritmética política, orden natural, libertad de comercio, interés individual...) y un mejor conocimiento de la realidad económica europea explican la renovación doctrinal que se aprecia en los "economistas" del XVIII. En su Bosquejo económico (1750), Campomanes, además de incorporar el principio del interés particular como móvil de las decisiones individuales y de afirmar la subordinación de la riqueza pública a la privada — "para ser rico el monarca, es necesario lo sean los vasallos»-, advertía sobre los límites de las reformas:

\footnotetext{
3 Vid. Francisco Gómez Camacho, Economía y filosofía moral: la formación del pensamiento económico europeo en la escolásticas española, Sintesis, Madrid, 1998, pp. 85-108; Nieves San Emeterio, "Una revisión de los fundamentos sobre la pobreza", Revista Crítica de Ciencias Sociales y Jurídicas, n. ${ }^{\circ}$ 28, 2010, p. 4; Luis Perdices de Blas y J. Reeder, "Debate sobre el socorro a los pobres", en L. Perdices de Blas y J. Reeder (eds.), Diccionario de pensamiento económico en España (1500-2000), Fundación ICO, Madrid, 2003, pp. 212-219.

4 Vid. Ángel García Sanz, "El contexto económico del pensamiento escolástico: el florecimiento del capitalismo mercantil en la España del siglo XVI", en E. Fuentes Quintana (dir.), Economía y economistas españoles. 1. De los orígenes al mercantilismo, Funcas, Barcelona, 1999, pp. 131-163; Marjorie Grice-Hutchinson, El pensamiento económico en España, 1177-1740, Crítica, Barcelona, 1982, pp.163 y ss.

${ }^{5}$ Luis Perdices, La economía politica de la decadencia de Castilla en el siglo XVII, Síntesis, Madrid, 1996.
} 
No es mi ánimo promover aquí la igualdad de bienes en todos los individuos. La sociedad y el orden de estados en la república tiene su principal apoyo en esta desigualdad [...]. Pretendo, sí, únicamente, evitar aquella suma desigualdad que hace de la mayor parte de los vasallos unos míseros colonos ${ }^{6}$.

Entre las nuevas categorias analiticas pronto se hizo común la de "felicidad pública». Se apelaba con ella a un crecimiento económico que, a través del mercado, compatibilizaba interés público y privado; una felicidad entendida, dirá Jovellanos, no en sentido moral, sino material: "aquel estado de abundancia y comodidades que debe procurar todo buen gobierno a sus individuos". Dadas las restricciones al libre funcionamiento del mercado, se reclamaba de la "mano visible" del Estado tanto la facultad de reducir las resistencias sociales al cambio como la de combatir las desigualdades que amenazaban con cuestionar la estabilidad social y política. Pobreza y desigualdad entrarán así de lleno en la agenda política del reformismo borbónico. Ahora bien, lo harán dentro de unos límites y de un gradualismo que, en el caso del Expediente de Ley Agraria (1766), Campomanes acertó a expresar con certeras palabras: "nada se debe tocar en el dominio, y todo se debe remediar en los arriendos", o, lo que es lo mismo, se trataba de "enmendar por medios suaves e indirectos la desigualdad en las labranzas". Esa misma moderación se aplicará en otros debates sectoriales: caso de los gremios, del libre comercio de granos, de la abolición del monopolio gaditano en la "carrera" de Indias, o de la reforma fiscal.

\subsection{Ilustración tardia: de la "felicidad pública" al uinterés particular", 1788-1808}

Dos escenarios presiden la coyuntura histórica de esta etapa. Desde el económico, las guerras contra Inglaterra y Francia, el cierre de los mercados coloniales y la quiebra fiscal del Estado abrian una etapa contractiva y de inestabilidad social. Desde el escenario político, las revoluciones francesa y norteamericana introducirán en la economía politica el interés por el iusnaturalismo racionalista - pacto social, soberanía, derechos naturales... - . Por tales vías, el debate constitucional llegará a adquirir carta de naturaleza en la prensa, la magistratura y la economia 7 , abriendo paso a una Ilustración "radical" (Maravall, Elorza) de la que Arroyal será referente: "la felicidad pública de un reino proviene de su buena o mala constitución" 8 .

En el caso de la prensa, El Censor, al tratar sobre desigualdad, remitía a un orden político respetuoso con el "interés particular" y con la igualdad jurídica no de rentas, "que la naturaleza ni la ha establecido ni la quiere"-. Además, se incorporaban otros matices: la riqueza ha de ser fruto del trabajo, habiendo de

\footnotetext{
6 Pedro Rodríguez Campomanes, Bosquejo de política económica española delineado sobre el estado presente de sus intereses (1750), Editora Nacional, Madrid, 1984, ed. de J. Cejudo, pp. 58 y 64.

7 Jesús Astigarraga, "El debate sobre las formas de gobierno en las 'Apuntaciones al Genovesi' de R. de Salas", Revista de Estudios Politicos, n. ${ }^{\circ}$ 144, pp. 11-46; Javier Fernández Sebastián, "Igualdad", en Diccionario politico y social del siglo XIX español, Alianza, Madrid, 2000, pp. 360371 .

8 León de Arroyal, Cartas económico-politicas al conde de Lerena (1786-1795), Madrid, 1968, p. 65.
} 
aspirarse a la "medianía de fortunas»9. En 1786, Nipho, desde la Estafeta de Londres, introducía la frugalidad y el ahorro como antidotos a la pobreza en un momento en que la economía clásica proponía el salario y el mercado laboral como alternativas al coste de oportunidad social que representaban la limosna o el gasto asistencial. Ese mismo ideario será el que comience a difundirse desde la Décade Philosofique (1794-1807), órgano de expresión de los discipulos de Say y extractado desde 1803 en España en las páginas de Variedades de Ciencia, Literatura y Artes $^{10}$. También el Semanario de Agricultura y Artes (1797-1808) filtraba los valores asociados a la sociedad industrial a través de las reseñas de las obras de Rumford, Crumpe o Bentham.

Junto al debate social, también el constitucional se dejará oír en la literatura política —Ibáñez de la Rentería, Albosía o Aguirre11_. Para Foronda, en los "estados despóticos", donde están sofocados los derechos naturales, "no hay el menor rastro de industria", en tanto que para Pedro Antonio Sánchez, "en un estado republicano, el pueblo, por lo común, es menos pobre" que en uno monárquico. En el Elogio del conde de Gausa (1786), Cabarrús precisaba aún más: "en las naciones más florecientes apenas hay absoluta pobreza porque hay fuerzas que, luchando entre si, van alterando y restableciendo la igualdad» ${ }^{2}$.

Por último, y ya en el campo de la economía política, su matriz analítica se nutrirá de dos aportes doctrinales: iusnaturalismo racionalista y economía clásica. El iusnaturalismo, además de ofrecer una filosofia secularizada de los derechos de propiedad, cimentará los principios del constitucionalismo liberal, erigiendo la propiedad en el vínculo legitimador de la ciudadanía y de los derechos políticos. Y así, reconocida la exclusividad de propiedad, la desigualdad dejará de contemplarse desde la perspectiva teológica (caridad, limosna) para ser objeto de tratamiento por las leyes civiles (leyes de pobres). Por su parte, la economía clásica -entre 1790 y 1808 transcurren en España los años de difusión de la obra de A. Smith- ofrecía una teoría económica capaz de explicar el crecimiento a partir

\footnotetext{
9 El Censor: Discursos XXI (1781), CLIX (1787) y CLXIII (1787). Las citas, en José Miguel Caso González (ed.), El Censor, obra periódica comenzada a publicar en 1781 y terminada en 1787, Instituto Feijoo de Estudios del Siglo XVIII, Universidad de Oviedo, 1989. Sobre el mismo tema, Adrián Schubert, "Charity Properly Understood: Changing Ideas about Poor Relief in Liberal Spain", Comparative Studies in Society and History, vol. 33.1, 1991, pp. 36-55.

$10 \mathrm{Vid}$. M. $^{a}$ Luisa Sánchez Mejīa (ed.), Textos politicos de los ideólogos: Cabanis y Destutt de Tracy, Centro de Estudios Políticos y Constitucionales, Madrid, 2004; Alfonso Sánchez Hormigo, "Los ideólogos, el pensamiento económico y la revolución francesa en España (1800-1808)", en A. Sánchez Hormigo (ed.), En la estela de Ernest Lluch: ensayos sobre historia del pensamiento económico, Gobierno de Aragón-Fundación E. Lluch, Zaragoza, 2006, pp. 83-104.

11 En la literatura política, los discursos de Ibáñez de la Rentería (1790), la obra de J. de Albosía o las cartas del Militar Ingenuo (1787) de M. de Aguirre, actualizan el debate sobre formas de gobierno / organización social y desigualdad. Vid. José M. Portillo Valdés, "Constitucionalismo antes de la constitución. La economía politica y los orígenes del constitucionalismo en España", Nuevo Mundo, 2009 (revues.org./ cnrs, EHESS); Ignacio Fernández Sarasola, Proyectos constitucionales en España (1786-1824), Centro de Estudios Políticos y Constitucionales, Madrid, 2004; Jesús Astigarraga, "El debate sobre las formas de gobierno en las "Apuntaciones al Genovesi" de Ramón de Salas”, op. cit.

12 Para las citas, Ignacio Fernández Sarasola (ed.), V. de Foronda (1789-1794): escritos politicos y constitucionales, UPV, 2002, pp. 92-99; Pedro A. Sánchez, "Memoria sobre la mendicidad" (1783), en Xosé M. Beiras (ed.), La economía gallega en los escritos de Pedro Antonio Sánchez, Galaxia, Vigo, 1973, p.62.
} 
del ejercicio del self-interest en un entorno institucional respetuoso con la libertad y derechos de propiedad. Desde este momento, "la ortodoxia económica dejará de preguntarse el porqué de la propiedad: la propiedad privada y su garantía por el Estado pasan a ser supuestos implicitos sobre los que se construye la nueva ciencia» 13 .

Jovellanos proporciona un excelente observatorio desde el que analizar los esfuerzos por conciliar "interés particular" - "consignado en las leyes de la naturaleza" y al que el hombre debe "su conservación y el fundamento de su propiedad" - y "felicidad pública". ¿Bastará, se preguntaba, "la continua lucha de intereses a restablecer naturalmente el equilibrio que jamás podrian alcanzar las leyes"? Siendo evidente que esa lucha favorecía la "acumulación de fortunas", Jovellanos optará por una posición intermedia entre las tesis de A. Smith y las de Montesquieu: aduciendo razones de utilidad social, admitirá márgenes para la intervención pública ${ }^{14}$.

Pero había más escollos que salvar: ¿cómo conciliar los nuevos principios de movilidad social con el viejo orden estamental? Para Sistiernes o Foronda, los estamentos representaban la "esencia y constitución social del estado". Respecto a los fundamentos de ese orden - amortización, mayorazgos...- y a su posible reforma, las propuestas de Jovellanos en el Informe de Ley Agraria (1795) habían sido calificadas por Cabarrús de "condescendencia lamentable" con los "poderosos» 15 .

Sea lo que fuere, la influencia de A. Smith se generaliza en estos años. Lucas Labrada estimaba que el laissez-faire social — "déjese actuar a la naturaleza y no se proteja a cualquiera de los extremos" - conduciría de forma natural a la "multiplicación de las fortunas medianas". Alcalá Galiano, haciendo suya la filosofia liberal de la historia, asociaba la propiedad comunal con el "estado salvaje». Para Ramón Campos, las desigualdades naturales (de haberes, de cuna, de sexo u oficio) eran "la máquina que la naturaleza emplea para mejorar la especie» en un proceso en el que "la mecánica del interés" conducía necesariamente a una sociedad donde "las clases medias serán las que den ley» ${ }^{16}$. En otro extremo analítico

13 Nieves San Emeterio, Nieves, Sobre la propiedad. El concepto de propiedad en la Edad Moderna, op. cit.

14 Las citas, en Jovellanos, "Informe de Ley Agraria" (1795), en Vicent Llombart y Joaquín Ocampo (eds.), Jovellanos. Obras completas. X. Escritos económicos, Instituto Feijoo de Estudios del Siglo XVIII, Oviedo, 2008, pp. 703-4. Para el tema que se analiza, J. H. Polt, "El pensamiento económico de Jovellanos y sus fuentes inglesas”, Información Comercial Española, n. ${ }^{\circ}$ 512, 1976 , pp. 23-57.

15 Francisco Cabarrús, "Carta IV (1792)", en José A. Maravall (ed.), Conde de Cabarrús: cartas, Castellote, Madrid, 1973, p. 223. En el oficio de remisión del informe a la Matritense confesaba Jovellanos no haber llegado "al sublime punto a que los principios podian conducirme; pero la moderación, sobre oportuna, me parecía necesaria. La perfección del hombre, así en moral como en politica, es progresiva y suele adelantar poco cuando quiere andar demasiado. Nada es tan dificil como postrar de un golpe los errores autorizados y protegidos, y para destruir las opiniones, es tal vez más seguro debilitar poco a poco su raíz que abatir el tronco...". Cfr. Vicent Llombart y Joaquín Ocampo (eds.), Jovellanos. Obras completas. X. Escritos económicos, op. cit., p. 828.

16 Las citas, en Lucas Labrada, Descripción económica del Reino de Galicia (1804), Galaxia, Vigo, 1971, ed. de F. Río Barja, pp. 205-6; Vicente Alcalá Galiano, Sobre la economía politica y los impuestos (1781-1788), Segovia, 1992, ed. de J. M. Valles Garrido, pp. 302-4; Ramón Campos, De la desigualdad personal en la sociedad civil (1799), Instituto J. Gil Albert, Alicante, 1989, p. 9. 
se situaban quienes, con argumentos rousseaunianos, argumentaban contra la desigualdad desde la economía moral. Así, para Manuel de Aguirre, la gran propiedad se consagraba a costa de "la aniquilación campesina", términos similares a los que se leen en las cartas de Arroyal — "las grandes riquezas de los particulares son siempre despojos del común"- o en los Discursos forenses (1787) de Meléndez Valdés.

\section{LAS CORTES DE CÁDIZ Y CONSAGRACIÓN POLÍTICA DE LA DESIGUALDAD, 1808-1814}

En los diversos proyectos constitucionales que antecedieron al de Cádiz ${ }^{17}$, las críticas al Antiguo Régimen se centraban más en los aspectos institucionales que en los económicos. Los proyectos de Aguirre y Arroyal insistirán en el ideal ilustrado de una sociedad rural de labradores independientes. En ese mismo sentido, en el decreto de 18 de agosto de 1808, de Jose I, se señalaba expresamente que la propiedad conducia a "mejorar los hombres y a unirlos más intimamente al gobierno". La excepción la ofrecerá Flórez Estrada. En Constitución para la nación española (1809) sostenía que "es preciso que la constitución favorezca a todas las clases", pues "todos los males de las sociedades" no tienen otro origen que la desigualdad de fortunas. En el Examen imparcial (1811), Flórez denostaba la desamortización de 1798: las tierras se habian entregado a cambio de deuda haciendo que "muchos capitalistas" se reconvirtiesen en "rentistas", quedando así las "fortunas de los ciudadanos tanto o más desniveladas" 18 .

Aun cuando en la Consulta al pais (1809) fueran generalizadas las denuncias de la amortización o las críticas a las oligarquías locales - sin que falten algunas voces (Dou, Capmany) contrarias al "absurdo político" de la soberanía nacional 19_, su alcance quedaba limitado por el propio decreto de la consulta, en el que expresamente se señalaba que las reformas debian "asegurarse en las leyes fundamentales de la monarquía". En las Actas de la Junta de Legislación y de la Comisión de Constitución (1809-1811) resultan elocuentes las discusiones suscitadas sobre el alcance y contenidos del derecho de propiedad: la concesión de ciudadanía a extranjeros se condicionaba a que hubiesen adquirido bienes raíces; igualmente, la ciudadanía quedaría en suspenso en caso de "no tener empleo, oficio o modo de vivir conocido". Y ya convocadas las Cortes, las urgencias del momento obligarán, en palabras de Argüelles, a tomar decisiones "sin recurrir a doctrinas metafísicas ni mendigar de filósofos y escritores abstractos" ${ }^{20}$.

El vacío de poder ofrecía una oportunidad única para reparar la secular desigualdad de rentas. En el caso del sector agrario, el decreto de abolición de señoríos (1811) probaba el carácter transaccional de la liquidación del Antiguo Régimen. Como ha señalado Congost, los legisladores, al convertir los derechos señoriales y la propiedad "imperfecta" en derechos de propiedad particular, eran cons-

17 Vid. Ignacio Fernández Sarasola, Proyectos constitucionales en España (1786-1824), op. cit.

18 Álvaro Flórez Estrada, Obras, BAE, tomo CXIII, Madrid,1958, pp. 303-4, 317-320 y 121-123.

19 Las respuestas a la consulta, en Miguel Artola, Los orígenes de la España contemporánea, Instituto de Estudios Politicos, Madrid, II, 1976.

20 Agustín de Argüelles, Examen histórico de la reforma constitucional de España, Imp. C. Wood e Hijo, Londres, 1835, I, p. 188. 
cientes de que no pretendian cambiar las bases sociales sobre las que aquella se asentaba $^{21}$. El mismo sesgo social se aprecia en el decreto que en 1812 abolía las ordenanzas de montes y plantíos: la "fortaleza" de las tesis liberales se impondrán a los defensores de los usos y derechos consuetudinarios de los pueblos ${ }^{22}$. Y la misma dialéctica se reproducía en 1813, con ocasión el decreto de reducción de baldíos y comunes a propiedad particular: si para Toreno tal medida "aumentaría la riqueza de la nación", para Terrero o Calatrava aquellos terrenos, "propiedad exclusiva" de los pueblos, siempre se habían considerado "como el patrimonio de los pobres" 23 . El decreto "sobre medidas de fomento de la agricultura y ganadería", al establecer la libertad de arriendos, de cercamientos y de comercialización de excedentes, ponía fin al secular sistema de campos abiertos y de aprovechamientos comunes ${ }^{24}$. Pese a todo, en el discurso de la sesión de clausura se vindicarán tales reformas con estas palabras:

Después de haber puesto las piedras angulares del suntuoso edifico que ya se levanta de la prosperidad, de levantar a la nación de la esclavitud a la soberanía, de abolir los restos góticos del régimen feudal, las Cortes extendieron la liberalidad a los animales, a los montes y a las plantas, derogando ordenanzas y reglamentos contrarios al derecho de propiedad...25.

¿Qué se hizo en el caso de la industria? De las 6225 páginas de los diarios de sesiones, apenas 11 se ocupan de la industria. La marginación de los temas industriales ha de relacionarse con el interés en consolidar la "vía agraria" al capitalismo. Como señalara García Sanz, la aparente paradoja de que una burguesía teóricamente revolucionaria y admiradora del modelo constitucional francés acabara promoviendo la fortaleza nobiliaria a costa de la pauperización campesina no estaba exenta de racionalidad: aquella clase identificaba la maximización de sus beneficios más con el capitalismo agrario que con el industrial.

Dos textos próximos en el tiempo ofrecen un balance esclarecedor de estos años. En 1811, las Reflexiones sociales de Canga Argüelles advertían ya de la emergencia de la sociedad burguesa y de la necesidad de evitar, en el tránsito del

21 Vid. Rosa Congost, "Sagrada propiedad imperfecta. Otra visión de la revolución liberal española", Historia Agraria, 20, 2000, pp. 61-93. Como señalaba Argüelles, "¿Y se podrá decir que esa medida se dirige a establecer la democracia?, ¿qué tiene que ver esta medida con la jerarquía de clases?». Cfr. Francisco. Tomás y Valiente (ed.), Agustín de Argüelles. Discursos, Junta General del Principado de Asturias, Oviedo, 1995, pp. 967.

22 Toreno mantendrá: "Se ha dicho que, si se aprobase, se verían reducidos a un estado lastimoso los pueblos. Una piedad mal entendida ha suscitado esta discusión. La verdadera piedad del legislador consiste en dejar al hombre con las menos trabas posibles, y su interés le enseñará a dónde dirigir sus miras»: Diario de Sesiones de las Cortes Generales y Extraordinarias (DSCGE), 445-6 (21 y 22 /XII/ 1811), pp. 2457-2471.

23 Diario de Sesiones de las Cortes Generales y Extraordinarias (DSCGE), 329 (27/8/1811), pp. 1761-11705.

24 Vid. Manuel González Molina y A. Ortega Santos, "Bienes comunes y conflictos sociales en las sociedades rurales", Historia Social, n. ${ }^{\circ}$ 38, 2000, pp. 95-116; Felipa Sánchez Salazar, "La redefinición de los derechos de propiedad. A propósito de los decretos sobre cercados de las Cortes de Cádiz (1810-1824)", Historia Agraria, n. ${ }^{3} 39,2006$, pp. 207-240.

25 Diario de Sesiones de las Cortes Generales y Extraordinarias (DSCGE), 973 (14/IX/1813), p. 6.223 . 
feudalismo al capitalismo, los excesos de una Francia revolucionaria que habian convertido "la libertad en desenfreno, y la igualdad, en monstruoso desconcierto" 26 . Como contrapunto, en Teoría de las Cortes (1813), Martínez Marina expresaba la estrecha relación entre economía e instituciones: una legislación "que sacrifica una parte de los ciudadanos" y que impide "la igualdad de fortunas y un sabio y uniforme repartimiento de tierras y propiedad" limitaba el crecimiento económico. Tras denunciar las expectativas depositadas en la Constitución algunos "quisieran que la constitución hubiese abolido claramente las clases y cuerpos privilegiados"- y la persistente "tirania de los poderosos en los pueblos", concluía con escepticismo que, "después de tantas revoluciones, son pocos los pueblos que han mejorado su condición" ${ }^{27}$.

\section{LIBERALISMO, PROPIEDAD Y DESIGUALDAD, 1814-1830}

Es la paradoja más monstruosa: los pueblos en donde debería reinar con la mayor exaltación el afecto a las nuevas instituciones y al espiritu liberal, son en los que se ha asentado el aborrecimiento a la Constitución (1821) 28

El exilio liberal, el conocimiento directo de las experiencias políticas y constitucionales europeas, así como la influencia de la economía clásica, son coordenadas indispensables a las que referir el discurso político y económico sobre la desigualdad en esta etapa. Sin olvidar el propio contexto económico español de estos años. Años en los que la "marea roturadora", el proteccionismo triguero o el rechazo al pago de diezmos, apenas pudieron compensar los efectos negativos de la deflación, de la reducción del gasto público, y de la crisis manufacturera y de la agricultura comercial exportadora.

\subsection{La economía política como ciencia neutral}

De 1808 a 1835 se extiende en España la "era Say", cuyo Tratado (1803) y Catecismo (1815) serán reiteradamente traducidos y editados ${ }^{29}$. Además de su carácter didáctico y divulgativo, ambas obras poseian valores añadidos que explican su éxito: ofrecía una visión optimista e industrialista del crecimiento econó-

26 Cfr. C. García Monerris (ed.), José Canga Argüelles. Reflexiones sociales y otros escritos, Centro de Estudios Politicos y Constitucionales, Madrid, 2000, pp. 12 (nota 3), 19-20 (nota 8) y 37 (nota 20), y Fabián Estapé, “Canga Argüelles y el pensamiento económico liberal español”, en Ensayos sobre historia del pensamiento económico, Ariel, Barcelona, 1971, p. 101.

27 Cfr. José A. Escudero, Francisco Martinez Marina. Teoria de las Cortes, 2 vols., Junta General del Principado de Asturias, Oviedo, 2002, I, pp. 133, 136 -8 y 145.

28 Cfr. Manuel Ardit Lucas, Revolución liberal y revuelta campesina, Ariel, Barcelona, 1977, pp. 276-7. Sobre la misma cuestión, Jaume Torras, Liberalismo y rebeldía campesina, Ariel, Barcelona, 1976 , pp. 7-31.

29 Salvador Almenar, "El desarrollo del pensamiento económico clásico en España”, en E. Fuentes Quintana (dir.), Economía y economistas españoles. 4. La economía clásica, op. cit., pp. 7-92; Fernando López Castellano, "La reception de Say et son influencie sur l'institutionnalisation de l'enseignement de l'économie en Espagne (1807-1856)", en Revue d'Histoire des Sciencies Humanines, n. ${ }^{\circ}$ 21, 2009, pp. 127-151; José L. Malo Guillén, "Utopía y economía liberal", en Manuel Suárez-Cortina (ed.), Utopías, quimeras y desencantos. El universo utópico de la España liberal, Universidad de Cantabria, 2008, pp. 191-221. 
mico, una perspectiva armónica de la distribución de la riqueza y un desplazamiento del conflicto social desde la desigualdad de propiedades a la de "talentos".

Dos notas individualizan la economía politica de estos años. En primer lugar, la aspiración a dotar de neutralidad científica al discurso económico. Consideradas propiedad y desigualdad como dadas - excepción hecha de Flórez Estrada-, el paso siguiente será aceptar que los automatismos del mercado y el crecimiento económico acabarían por resolver el conflicto social. Para Manuel María Gutiérrez, la economía politica "considera la propiedad como una cosa de hecho, y solo accidentalmente atiende a su origen y consecuencias". López de Peñalver sostenía que la intervención pública debería limitarse a los casos en que "el interés particular tarda un tiempo inmenso en restablecer la proporción entre la producción y el consumo". Orense, además de vincular ciudadanía con "clases útiles", hacía suyas las tesis de Say relativas a que la economía politica "prescinde de todo cálculo político y de toda forma de gobierno": con la sola aplicación de los principios de la ciencia económica "se destierra la pobreza". La misma idea -la viabilidad de reformas económicas respetuosas con las relaciones sociales- se reiterará en Jaumeandreu ${ }^{30}$. Para Valle Santoro, la economía debe conciliar "los principios modernos de los economistas con nuestros usos y costumbres" y, por lo mismo, el economista deberá "atemperarse al estado y movimiento de las cosas, a la conservación y seguridad de la propiedad» 31 .

La abdicación del objetivo ilustrado de la "felicidad pública" — compatibilizar crecimiento y distribución de la renta- se hace evidente al considerar los instrumentos de intervención de carácter social. Como ha señalado Comín, desde el punto de vista de la beneficencia, "los liberales españoles trataron la pobreza con menor condescendencia que los poderes públicos del Antiguo Régimen»: dada la ausencia de un mercado de seguros o de ahorro, las sociedades de socorros serán en las regiones industriales la única alternativa ante la falta de cobertura social ${ }^{32}$.

La segunda nota se refiere al hecho de que la economía politica se hará portavoz de los valores de la sociedad industrial. Si en 1812 Franco Salazar consideraba la mendicidad como "enemiga de la industria", en 1829, Valle Santoro demandaba una "policía exacta y rigurosa" de pobres. Como se dijo, el acceso a la ciudadanía se condicionaba a la pertenencia a las "clases útiles". La nueva sociología del trabajo no dejará de dotarlo de nuevos atributos: laboriosidad y ahorro como antídotos frente a las crisis cíclicas y el paro; vinculación entre trabajo y

30 Las citas, en Manuel M. ${ }^{a}$ Gutiérrez, Epitome de los Principios fundamentales de la economía politica por J. B. Say, Imp. M. Collado, Madrid, 1816, p. 7; Juan López de Peñalver, "Reflexiones sobre la variación del precio del trigo" (1812), en Ernest Lluch (ed.), Juan López de Peñalver. Escritos económicos, Instituto de Estudios Fiscales, Madrid, 1992, p. 103; Casimiro Orense, Lecciones de Economía Politica sobre población, Imp. Vega, Madrid, 1820, p. 5; Eudaldo Jaumeandreu, Rudimentos de Economía Politica (1816), Alta Fulla Barcelona, 1988, ed. de E. Lluch, p. 5.

31 Las citas, en Francisco de Gregorio (marqués de Valle Santoro), Elementos de economía politica con aplicación particular a España, Imp. Vergés, Madrid, 1829, p. 42; José M. ${ }^{a}$ Vadillo, Discursos económico-políticos (1829-1844), Imp. D. Ferro, Madrid, 1844, pp. 3 у 52.

${ }^{32}$ Francisco Comín, "Los economistas clásicos y los políticos liberales ante los problemas de la economía española (1808-1874)", en E. Fuentes Quintana (dir.), Economía y economistas españoles: 4. La economía clásica, op. cit., pp. 694 y 670. 
salud - "en las provincias activas y laboriosas, en los semblantes se traduce el vigor y el brío»-, y entre trabajo y "luces, gusto y comodidad» ${ }^{3}$.

Además, los economistas no dudarán en tomar partido ante los debates de mayor actualidad -defensa del maquinismo o condena de la "asociación" obrera-, sin que falten las primeras llamadas de atención hacia los riesgos sociales asociados a la industria. Frente a tales riesgos, se apelará de nuevo al ahorro y al óptimo social representado por las "fortunas repartidas" (Negrete, Canga Argüe1les). En Flórez Estrada, la premisa de que las "clases medias" eran las "más productoras de riqueza" era inseparable de la consideración de la desigualdad como restricción a la prosperidad y estabilidad social.

\subsection{La economia politica como ciencia social}

Cuando los labradores y artesanos no tienen participación alguna en las tierras que cultivan ni en los productos fabriles que elaboran, no es verosimil que respeten las leyes. Desean con ansia un nuevo orden de cosas

(Flórez Estrada, Curso de economía politica ${ }^{34}$ )

El Curso de Economía Politica se convirtió pronto en la obra más representativa e influyente de la economía politica española. La singularidad del Curso frente a otros tratados fue fruto de la voluntad del autor, que ya en el "Discurso preliminar" expresaba su compromiso con una ciencia que "abraza el sistema social entero". Pero la especificidad más significativa aparecía al exponer el modelo de crecimiento clásico: los factores tópicos -ahorro, división del trabajo/productividad, extensión del mercado...- se matizaban al vincular acumulación de capital con la distribución de la propiedad. En el capítulo tercero — "De la inviolabilidad de la propiedad..."- diferenciaba Flórez entre el derecho de propiedad sobre la riqueza fruto del trabajo - derecho natural inviolable- y aquel otro ejercido sobre los recursos naturales - alterable en la medida en que es fruto de leyes positivas-. Almenar vincula la raiz de sus tesis sobre la propiedad con un "republicanismo ilustrado" que, como en Mably, conduce a la defensa de la igualdad como condición previa al ejercicio de las virtudes cívicas y de la cohesión so$\mathrm{cial}^{35}$.

33 Cfr. Franco Salazar, Restauración politica, económica y militar de España, Imp. Sancha, Madrid, 1812, p. 233; Francisco de Gregorio (marqués de Valle Santoro), Elementos de economía politica con aplicación particular a España, op. cit., p. 278; Casimiro Orense, Lecciones de Economía Politica sobre población, op. cit., p. 15; Manuel Antonio Gutiérrez (1816), Epitome de los principios fundamentales de economía politica de Juan Bautista Say, Imp. Collado, Madrid, 1816, p. 79; Agustín Pascual, Cartilla de economía politica o Instrucción familiar que manifiesta cómo se producen, distribuyen y consumen las riquezas. Obra fundada en hechos y útil a toda clase de personas. Escrita en francés por Juan Bautista Say, Imp. Real, Madrid, 1816, p. 162; Ramón Lázaro Dou, La riqueza de las naciones nuevamente explicada con las doctrinas de su mismo investigador, Imp. de la Pontificia y Real Universidad, Cervera, 1817, p. 133; José Canga Argüelles, Elementos de la ciencia de la Hacienda (1825), Instituto de Estudios Fiscales, Madrid, 1961, p. 17.

34 Cfr. Salvador Almenar (ed.), Curso de Economía Política, Trea, Gijón, 2010, p. 53.

35 Salvador Almenar, "A. Flórez Estrada: revolución y constitución, economía política y cuestión social”, en Almenar, Salvador (ed.), Álvaro Flórez Estrada. Curso de Economía Política, op. cit., pp. 63-149. 


\subsection{La desigualdad en el debate político-constitucional}

Los años del Trienio apartaron al campesino de la causa liberal: el motín de Alcoy (1821) será un ejemplo entre muchos. Fontana, al referirse al período 18231833, sugería que el derribo del Antiguo Régimen, más que a los liberales, debía atribuirse a la movilización campesina: su negativa al pago de rentas instrumentalizada por el bando apostólico- será la que convenza a las oligarquías agrarias de que el liberalismo resultaba, comparativamente, un mal menor ${ }^{36}$.

Desde 1820 se hace ya perceptible la reelaboración del discurso liberal frente a los excesos del doceañismo y del iusnaturalismo contractualista. Burke, Bentham, Royer-Collard, Constant o Guizot se convierten en referencias obligadas en la prensa y en el debate político. Desde El Censor y El Imparcial, Miñano y Javier de Burgos acertaron a expresar los valores del liberalismo doctrinario ${ }^{37}$. A ojos de ese ideario, la industrialización se presentaba como un proceso moderador de la desigualdad en el seno de una sociedad "mercantil» en la que, según Martínez de la Rosa, el "verdadero pueblo" se asociaría a los "pacíficos propietarios y artesanos industriosos", soportes, todos ellos, de una "monarquía moderada", de un "régimen templado" de libertad y orden ${ }^{38}$.

El constitucionalismo, alimentado por las traducciones de Bentham, Constant y Destutt de Tracy, será foro privilegiado del discurso social y político. En 1821, Salas publicaba Lecciones de Derecho Constitucional. Frente al positivismo jurídico de Bentham, quien calificaba de "ilusión metafisica" los derechos naturales, Salas defendía el origen natural de los derechos subjetivos, entre ellos el de propiedad. Sobre la desigualdad, considerada inevitable, no excluía la actuación del gobierno con vistas a alcanzar una "igualdad razonable" o "practicable». Con los ideólogos, cree que la Constitución debía eliminar los privilegios de las "clases devoradoras" para hacer posible una sociedad industrial y comercial que compatibilizase el crecimiento con la atenuación de las diferencias de renta ${ }^{39}$.

36 Josep Fontana, La crisis del Antiguo Régimen, 1808-1833, Crítica, Barcelona, 1979, pp. 2728. Sobre la misma cuestión, José del Moral Ruiz, Hacienda y sociedad en el Trienio constitucional, 1820-1823, Instituto de Estudios Fiscales, Madrid, 1975, y M. ${ }^{\mathrm{a}}$ Cruz Romeo Mateo, Entre el orden y la revolución. La formación de la burguesia liberal en la crisis de la monarquía absoluta, $1814-$ 1833, Instituto J. Gil Albert, Universidad de Alicante, 1993.

37 Vid. Luis Díez del Corral, El liberalismo doctrinario, 2. ${ }^{a}$ ed., Instituto de Estudios Políticos, Madrid, 1956; Antonio Elorza, "La ideologia moderada en el Trienio liberal", Cuadernos Hispanoamericanos, n. ${ }^{\circ}$ 288, 1974, pp. 584-650; Javier Fernández Sebastián, "Liberales y liberalismo en España, 1810-1850", Revista de Estudios Políticos, n. ' 134, 2006, pp. 129-176; Ignacio Fernández Sarasola, "El primer liberalismo en España (1808-1833)”, Historia Contemporánea, n. ${ }^{4} 43$, 2011, pp. 547-583.

38 "Toda nación es libre desde el momento en que es industriosa. A proporción que se multiplican las riquezas se hacen más semejantes las clases de la sociedad": El Censor, VI, 1821. Cit. en Antonio Elorza, La ideología moderada en el Trienio liberal, op. cit., pp. 584 y ss.

39 Vid. Pedro Schwartz, "La influencia de J. Bentham en España", ICE, 517, 1976, pp. 37-57; M. ${ }^{a}$ L. Sánchez Mejía, Textos politicos de los ideólogos: Cabanis y Destutt de Tracy, Centro de Estudios Políticos y Constitucionales, Madrid, 2004; Alfonso Sánchez Hormigo, "Los ideólogos, el pensamiento económico y la revolución francesa en España (1800-1808)", en A. Sánchez Hormigo (ed.), En la estela de Ernest Lluch: ensayos sobre historia del pensamiento económico, Gobierno de Aragón-Fundación E. Lluch, Zaragoza, 2006, pp. 83-104; P. Sánchez Garcia, "Lecturas de Bentham en España (1820-1823)", en M. ${ }^{a}$ del C. García Tejera et al. (ed.), Lecturas del pensamiento 
En sentido opuesto y en línea con Constant, Marcial López -Curso de Politica Constitucional de Benjamin Constant (1821) - y E. Jaumeandreu -Curso elemental de Derecho Público (1820) - sostendrán la necesidad de una monarquía moderada como representación de la "hermosa clase de los propietarios": "bajo su régimen, las clases laboriosas no tendrán que temer ningún género de opresión". Toribio Núñez se apoyará en Bentham para legitimar un orden social alejado de radicalismos: partiendo de que "no hay propiedad natural" y dando por sentado que la existente es "únicamente obra de las leyes", concluye que estas últimas no deben sino proteger la riqueza: la pobreza "no es obra de las leyes, sino del hombre fuera de la sociedad". Actuando así, se alcanzaria un orden social en el que "las clases que viven en la medianía y que son las más ventajosas" ampliarian su fortuna a expensas de las clases más poderosas ${ }^{40}$. Y es que, ante el pauperismo derivado de la industrialización y frente a los "economistas del desencanto" recuérdese que las previsiones de Malthus y Ricardo llevaron a Carlyle a calificar a la economía como "the dismal science"-, Bentham ofrecia un consenso seductoramente simple: su empirismo ético —el bien individual asimilado al interés particular - ofrecia una filosofia social que sustituía la equidad por la eficiencia y que, por lo mismo, permitía conciliar objetivos económicos y sociales al margen de prescripciones normativas.

Y también con Bentham como telón de fondo redactará Martínez Marina sus Principios (1824). Al rechazo a la viabilidad de toda sociedad o gobierno que ampara leyes que "autorizan las más monstruosas diferencias y desigualdades en las fortunas" se unía su oposición a todo género de laissez-faire social: admitiendo que la igualdad es "una especulación", no puede dejar de establecerse que debe existir "entre todos los miembros del cuerpo social una igualdad relativa". A las críticas a Bentham sumaba las dirigidas a Constant, quien consideraba la propiedad como "convención social sagrada e inviolable, anterior a la sociedad e independiente de ella ${ }^{41}$.

filosófico, estético y religioso (XII Encuentros de la Ilustración al Romanticismo, 1750-1850), Universidad de Cádiz, 2007; Ignacio Fernández Sarasola, "Ramón de Salas y la nueva ciencia jurídica”, Teoría y Realidad Constitucional, n. ${ }^{\circ} 28,2011$, pp. 633-648; Raúl Morodo, Sobre R. de Salas y E. Jaumeandreu: tradición, ilustración y liberalismo, Real A. de Ciencias Morales y Políticas, Madrid, 2013.

40 Cfr. Toribio Núñez, Ciencia social según los principios de Jeremías Bentham, Imp. Real, Madrid, 1835, pp. 354-359

41 Tras diferenciar entre la propiedad natural fruto del trabajo y la propiedad "facticia o legal", añadía: "Aunque la Política debe hacer respetar este género de Propiedad, señaladamente cuando es conforme a principios de justicia y utilidad pública (...), sin embargo, como muchas leyes vigentes en las sociedades de Europa han nacido en el triste y tenebroso invierno de la razón, y deben su origen a abusos del poder, el bien del Estado exige (...) corregir leyes viciosas y hacer las convenientes innovaciones y mudanzas en la Propiedad con el saludable objeto de promover la circulación de riquezas y una distribución más equitativa de fortunas". Cfr. Joaquín Varela SuanzesCarpegna (ed.), Francisco Martinez Marina: principios naturales de la moral, de la politica y de la legislación (1833), Junta General del Principado de Asturias, Oviedo, 1993, 2 vols., I, pp. 30-31, 35-36 y 41-42. 


\section{ECONOMÍA POLÍTICA Y “CUESTIÓN SOCIAL", 1833-1850}

Las revoluciones de 1830 y 1848 dejarán su impronta tanto en el discurso político como en el económico ${ }^{42}$. En España, los problemas asociados a la construcción del Estado liberal, la guerra carlista y los primeros episodios de agitación obrera y campesina proporcionaron factores añadidos de reflexión.

En el tratamiento de la "cuestión social" suelen diferenciarse dos corrientes doctrinales. Por un lado, la ortodoxa, asociada a la economía clásica y a la filosofia utilitarista, se rastrea en Inglaterra desde Malthus y Ricardo hasta el debate sobre la reforma de la ley de pobres en 1834, y en Francia, desde Say a Bastiat. En ambos casos, la nueva desigualdad, asociada a industrialización / maquinismo, se resolvía apelando al crecimiento económico y al ahorro. En el caso extremo de Bastiat se negaba el problema mismo: la "armonía natural" preside las relaciones sociales. La tradición heterodoxa y reformista se vincula al sansimonismo, al socialismo premarxista - las Questions sociales (1834) de J. Chevalier-, así como a otras propuestas de "economía social" surgidas al margen del ámbito académico. La recepción de las citadas corrientes doctrinales europeas desembocará en España en un pluralismo doctrinal -eclecticismo- al servicio de la causa liberal y que, como señalara Blanqui, aun "cuando nada ha inventado, suavizará las asperezas de las teorias absolutas" ${ }^{43}$.

\subsection{Respuestas políticas a la desigualdad: de la "libertad y orden" a las solu- ciones heterodoxas}

En El espíritu del siglo (1835), Martínez de la Rosa, dando por desaparecidos los "sistemas extremos", vaticinaba que el "espíritu mercantil e industrial" acabaría por hermanar libertad y orden a partir de un soporte constitucional que, como el inglés, descansase sobre los "intereses reales" y la utilidad. También Donoso Cortés apelaba a un constitucionalismo que, desterrado el "peligro democrático", hallase su base social en las "clases propietarias, comerciales e industriales a las que pertenece el ejercicio de la soberanía". Si para A. Alcalá Galiano en la "mesocracia está la fuerza y dirección del Estado", para Pacheco, las clases medias encarnaban los "intereses comunes" frente a las "clases ínfimas" - "quien está reducido a un jornal no puede pretender la consideración ni la estima pública»Balmes, la noción de orden se asociaba a "no hacer concesiones políticas" y a garantizar la "tranquila circulación de capitales que proporciona pan y trabajo a los obreros» ${ }^{44}$.

42 En Inglaterra, las obras de Malthus y Ricardo, anticipándose a los Principios de J. S. Mill, ensombrecian el optimismo en el crecimiento sostenido al dar entrada en la economía a los problemas derivados del desempleo y del maquinismo. En Francia, la influencia de Say dejará paso a economistas -Blanqui, Sismondi, Droz...- que, al considerar las crisis industriales como recurrentes, sembrarán dudas respecto a la viabilidad del equilibrio económico. En esa misma onda ha de entenderse la economía politica cristiana o "filantropía liberal" católica, con vínculos hacia el doctrinarismo de los Cousin o Guizot. Cfr. José M. ${ }^{a}$ Serrano Sanz, Alfonso Sánchez Hormigo y José L. Malo Guillén, "Las críticas a la economía clásica”, en E. Fuentes Quintana (dir.), Economía y economistas españoles. 5. Las críticas a la economía clásica, Funcas, Barcelona, 2001, pp. 7-124.

43 Cfr. Adolphe-J. Blanqui, Historia de la economía politica en Europa (1837), Imp. N. Arias, Madrid, 1839, p. 381

44 Cfr. Francisco Martínez de la Rosa, El espíritu del siglo, Imp. J. Jordán, Madrid, 1835, pp. 25-26; J. Álvarez Junco (ed.), Juan Donoso Cortés. Lecciones de Derecho Politico (1836), Centro de 
Los mismos tópicos se repetirán desde el discurso jurídico y el filosófico - de los tratados de derecho administrativo de Oliván (1843), Posada Herrera (1849) o Colmeiro (1850) a las Lecciones de filosofía ecléctica de T. García Luna (1843)-. Por todas estas obras discurrirá una misma matriz, la del eclecticismo, una filosofía "de fácil acceso" (Menéndez y Pelayo) que contribuía a proporcionar argumentos a un liberalismo incapaz de incorporar a su discurso el problema social, como así se deja ver en el articulado de la Ley de Vagos (1845) o del Código Penal (1848).

Las alternativas doctrinales representadas por la literatura sansimoniana y premarxista han sido calificadas por Schumpeter de "extracientificas»: no hay análisis económico, sino programas de reforma social que parten de supuestos no contrastados sobre el comportamiento humano o las posibilidades de la tecnología. El éxito del sansimonismo, añadía, residía en su "optimismo humanitario", en su glorificación del empresario y de la industria y en una filosofia de la historia la ciencia como agente del progreso- que resultaban tranquilizadores para el poder.

En España, la presencia de corrientes críticas o radicales se superpone al regreso del segundo exilio liberal, a las primeras movilizaciones obreras y al debate suscitado por la desamortización de Mendizábal ${ }^{45}$. De ellas, el industrialismo sansimoniano será el que encierre mayor calado doctrinal. Desde 1825, en Le Producteur y Le Globe se sentaban las bases de un discurso económico con deudas hacia Say - la economía politica al servicio de la causa industrial- pero que rompía anclajes con la economía clásica: frente al laissez-faire se proponía una vía de crecimiento basada en la asociación banca-industria y en la dirección de la economía desde el Estado, lo que era tanto como admitir el principio de la desigualdad natural de facultades y de derechos politicos, con el consiguiente rechazo del sufragio universal y de la democracia. Esta última, reducida a una "aristocracia del talento y de la industria" y encarnada en técnicos, científicos e ingenieros, gobernaría "para el pueblo y no por el pueblo". La lucha de clases cedía asi su testigo a la "asociación comanditaria de la industria y los banqueros". Entre tanto llegase el "golpe de estado industrial", pobreza y desigualdad habian de confiar su remedio a la "ilustrada filantropía". Todas las tesis de la escuela serán reproducidas desde 1835 por Covert-Spring desde El Propagador de la Libertad y El Vapor 46 .

El socialismo premarxista español, señala Elorza, se desenvuelve entre la efervescencia obrera barcelonesa de 1835 y la fundación del partido demócrata

Estudios Políticos y Constitucionales, Madrid, 1984, I, p. 311; Antonio Alcalá Galiano, Lecciones de Derecho Politico Constitucional, Boix, Madrid, 1843, p. 18; Jaime Balmes, "La aristocracia y la democracia en España (1844)", en Obras completas, VII: Escritos politicos, BAC, Madrid, 1946, VII, p. 467; José F. Pacheco, Lecciones de Derecho Politico Constitucional, Boix, Madrid, 1845, p. 74.

45 José L. Malo Guillén, “Utopía y economía liberal”, en M. Suárez-Cortina (ed.), Utopias, quimeras y desencantos. El universo utópico de la España liberal, op. cit., pp. 191-211.

46 Vid. Alfonso Sánchez Hormigo, "Economía politica y saintsimonismo en la época romántica”, en Sánchez Hormigo, A. (ed.), Joseph A. Covert-Spring. Escritos saintsimonianos, Instituto de Estudios Fiscales, Madrid, 1999, pp. 15-134, y Alfonso Sánchez Hormigo, "Saintsimonism and Economic Thought in Spain (1834-1838)", History of Economic Ideas, col. XVII, 2, 2009, pp. 121-154. 
(1849), en el que acabarian integrándose furieristas (Garrido, Cámara, Moya) y cabetianos (Clavé, Monturiol). Sus propuestas serán más de armonía que de reforma social: integran componentes morales y cristianos sin llegar a cuestionar los derechos de propiedad. Abreu, desde El Correo Nacional, sostenía que en el falansterio la propiedad estaría garantizada "a los dueños particulares de manera indestructible". Desde El Eco del Comercio (1847) y La Organización del Trabajo (1848) se alimentarán los mismos tópicos: la "asociación" como expresión de la "armonía que Dios destinó al mundo", la "inutilidad de las revoluciones" y el primado del "principio divino de igualdad", no la "absoluta o de comunidad", sino la "justa y natural" en la que cada asociado percibirá la "parte proporcional a la cantidad de su trabajo y del capital que haya invertido". Garrido confiaba en que la asociación entre trabajo, capital y talento atrajese "a las altas clases" para una reforma social pacífica enraizada en "el principio de fraternidad salido del cristianismo". En 1849, Sixto Cámara, en La cuestión social, enfatizaba las críticas al comunismo y a toda "doctrina niveladora" en tanto ignorantes de la desigualdad natural y de la "jerarquía, único principio de verdadera política social", mensaje similar al propuesto por Monturiol desde las páginas de La Fraternidad ${ }^{4}$.

\subsection{Las respuestas desde la economia politica: "eclecticismo" y filantropia liberal}

En 1837, A. Blanqui analizaba las dos corrientes doctrinales dominantes en la economía politica europea: la "escuela social" y la "ecléctica" ${ }^{48}$. Sugería que la primera surgía como respuesta a la "escuela industrial" (A. Smith, Say), fruto de la percepción de que ni el libre mercado ni la libertad de empresa conducían a la armonía social: el espectro del subconsumo, de las crisis industriales recurrentes y del pauperismo amenazaban tanto el crecimiento como la estabilidad social. Al referirse a la segunda, señalaba que "nada ha inventado" como no fuera "suavizar las asperezas de las teorias absolutas». Es decir, desde 1830, la economía politica clásica quedaba doblemente cuestionada: ni la "mano invisible" cumplía adecuadamente su función equilibradora, ni la pretendida universalidad de los principios liberales encontraban encaje en la singularidad y diversidad de los casos nacionales; de ahí la emergencia en Alemania de la llamada "economía del pueblo" (Rau, List).

Una y otra escuela, reflejo tanto de la equidistancia entre liberalismo y socialismo como de la prevención ante los brotes revolucionarios, tendrán ocasión de expresar sus discursos en los planos académico y doctrinal, registrando en ambos casos la doble aspiración a "nacionalizar" el análisis económico y a suministrar al Estado un soporte legitimador a su acción interventora. El eclecticismo, presente en las obras de Borrego, Valle y Colmeiro, es fiel reflejo de la "extendida prevención" (Almenar) ante la revolución liberal de los treinta y ante las primeras manifestaciones del socialismo; de ahí su apoyo a intervenciones públicas que equilibren progreso y estabilidad social.

47 Citas, en Antonio Elorza, Socialismo utópico español, Alianza Editorial, Madrid, 1970, pp. 546, 148, 160-2 y 217-218

48 Adolphe-J. Blanqui, Historia de la economía politica en Europa (1837), Imp. N. Arias, 1839, pp. 366-388. 
En relación al tratamiento de la desigualdad, Borrego se distancia de A. Smith y de Say — "por haber inhabilitado a los gobiernos para ejercer función económica útil" - y se aproxima a la obra de Rau, por cuanto dota a la economía de relativismo y la convierte en "ciencia esencialmente práctica" y de "contenido social". Para Valle, si el liberalismo "no ha sido beneficioso para la clase trabajadora", los "economistas filántropos" han dado argumentos al "fanatismo para desvirtuar la propiedad". De ahí su reivindicación de una "nueva escuela social" que, "templando doctrinas" y rechazando "con el más alto desprecio las soluciones utópicas", sea capaz de ofrecer las "garantías que entrelacen las grandes fortunas con las minimas". Por su parte, Colmeiro - que en la traducción del Curso de Economía Politica (1842) de Droz se mostraba admirador de Guizot y del eclecticismo como "fusión de las verdades hijas de todos los sistemas" - reclamaba, frente al laissez-faire y al socialismo, una vía reformista respetuosa con "los intereses creados, aun aquellos de cuya legitimidad no pueda darse otra razón que su propia existencia». Y, en línea con los historiadores liberales franceses de la época orleanista (Thiers, Mignet), apadrinará una concepción del progreso y del cambio histórico basados en una revisión de la revolución: esta habría de ser "suave, lenta y gradual", y dirigida "no a destruir intereses, sino a crearlos" 49 .

Esta reformulación de la economía politica conducía inevitablemente a una revisión de sus principios. En Borrego, en línea con Sismondi, el interés propio y la competencia "degeneran en daño a la riqueza y en perjuicio de la clase jornalera». Colmeiro apuesta por una intervención pública correctora de desequilibrios sociales, pues trabajo infantil, jornadas laborales extenuantes y maquinismo podrian llevar a la formación de "ligas encaminadas a excitar una subida artificial y violenta de los salarios". Simultáneamente, se echará mano de las viejas fórmulas del paternalismo industrial: costumbres morigeradas, higiene, educación, moralidad y "bancos de economías o de ahorros" como vía para hacer a los trabajadores "frugales, sobrios e industriosos" 50 .

Andrés Borrego, en La cuestión social, y Ramón de la Sagra, en Lecciones de Economía Social, con ocasión de denunciar el pauperismo de cuño industrial, coincidian en rechazar la filosofia social subyacente a la economía clásica "concurrencia ilimitada", libertad de empresa, abstención estatal...- en tanto origen de los males sociales. Pero, a diferencia de Sismondi, no impugnan tanto el orden capitalista (propiedad privada, jerarquía de clases) como el sistema industrial. De ahí que sus propuestas reformistas, al ser formuladas desde la "economía social "51 — con deudas hacia Pecqueur (Economía social, 1839), Villeneuve o

49 Las citas, en Andrés Borrego, Economía politica con aplicación a la reforma de aranceles de adunas, a la situación de la industria fabril en Cataluña, y al mayor y más rápido aumento de la

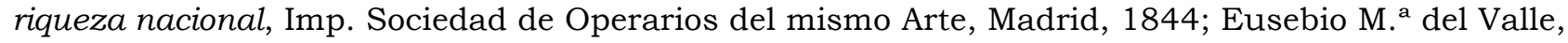
Curso de Economía Politica, Imp. del Colegio de Sordomudos, Madrid, 1842; Manuel Colmeiro, Tratado elemental de Economía Politica Ecléctica, Imp. Vd. ${ }^{a}$ e Hijos de Calleja, Madrid, 1845.

50 Cfr. José Canga Argüelles, Diccionario de Hacienda con aplicación a España (1834), op. cit., II, pp. $75-83$.

51 España no fue ajena a la "escuela social» en su versión filantrópica y cristina. La obra de Bargemont conoció rápida difusión. En el prólogo a su traducción, Soto y Barona contraponía los elogios a Lamennais, Chateaubriand, Donoso y Balmes con la descalificación de Proudhon, Fourier y Owen. En la "censura" inicial a la misma obra se achacaba a la economía política clásica el haber propagado el "materialismo" frente a la caridad y la resignación ${ }^{51}$. En definitiva, la lucha de clases se resolvía por vía moral: "la desigualdad es uno de los elementos del destino humano y 
Colins-, no alcancen a comprender el funcionamiento real de la economía y se limiten a propuestas normativas y de intervención pública.

Como en otros casos, el lado crítico estuvo representado por Flórez Estrada. En su debate con Sagra a propósito de la desamortización, se hará elocuente el abismo teórico entre ambos ${ }^{52}$. Flórez se mostraba contundente con la "secta" de la "escuela social", porque "ni ha impugnado las teorias de los economistas precedentes, ni justificado una nueva, ni resuelto ningún problema de economia". No existe, concluia, "escuela nueva" porque "no hay escuela sin teoria» 53 . Al rechazo a la teoría del valor-trabajo esgrimida por Sangra, añadía Flórez el dirigido a la carga reaccionaria de sus tesis sobre la propiedad: "¿qué importa —decía Sangra- que una porción de hombres se haya apoderado de los dones de la naturaleza si en ellos ha impuesto el sello de la propiedad?", idea que reiterará en sus lecciones ateneístas: "las desigualdades de fortunas pueden favorecer a las clases inferiores si las superiores desempeñan la santa y filantrópica misión que les está encomendada" 54 .

\section{CONCLUSIONES}

La brillantez analitica alcanzada por la filosofia escolástica en el tratamiento de temas como la historicidad de los derechos naturales o los límites al derecho de propiedad dio paso, con el mercantilismo, a una secularización de aquel análisis, más atento a sus implicaciones politicas y económicas. Desde 1760 y ante la creciente tensión población / recursos, la economía política se pondrá al servicio del reformismo borbónico: el objetivo de la "felicidad pública" será, nada menos, que el de conciliar desigualdad y "constitución económica" del reino.

El iusnaturalismo racionalista, activado por el debate constitucional y las graves crisis en que se hallaba sumida la monarquía, no fue suficiente para superar las resistencias sociales y políticas a cualquier reforma que alterase la distribución de la propiedad o la "constitución histórica" de la monarquía. Vacío de poder, guerra y revolución ofrecian una oportunidad histórica única para un arreglo institucional que alentase la sociedad de "fortunas medianas" por la que se venía clamando. No solo se desaprovechó tal oportunidad, sino que, con excepciones contadas, la economía política será instrumentalizada al servicio de la alianza entre la vieja aristocracia terrateniente y la burguesía aspirante a participar de la nueva propiedad "perfecta".

entra en los designios de la Providencia». La España de 1834, se decía, padece las consecuencias de haber recogido "la herrumbre de las doctrinas revolucionarias y antirreligiosas francesas", entre ellas la violación "de las propiedades más sagradas, el despojo del clero". Cfr. José Soto Barona, Economía politica cristiana o investigación sobre la naturaleza y causas del pauperismo en Francia y en Europa, y sobre los medios de socorrerlo y prevenirlo, Imp. La Esperanza, Madrid, 1852.

52 Vid. Salvador Almenar, "Propiedad, igualdad y prosperidad. Flórez Estrada y la desamortización", en R. Robledo (ed.), Historia de la propiedad: la expropiación, Universidad de Salamanca, 2012 .

53 Cfr. Álvaro Flórez Estrada, "La cuestión social, o sea, origen, latitud y efectos del derecho de propiedad" (1839), en Manuel Jesús González (ed.), Álvaro Flórez Estrada: Escritos politicos, op. cit., p. 6.

54 Cfr. Ramón de la Sagra, Lecciones de Economía Social, Imp. Ferrer y C. ${ }^{\text {, }}$ Madrid, 1840, p. 68. 
Tras las contrarreformas del sexenio absolutista, el Trienio retomó la marcha hacia la reforma agraria liberal. Voces críticas como las de Flórez Estrada o Martínez Marina replanteando la naturaleza diversa de los derechos de propiedad o los riesgos sociales de la polarización de rentas no hallaron eco. De ahí el asombro de muchos políticos ante la desafección popular hacia la causa liberal.

Desde 1833, al doctrinarismo liberal se unirá la economía ecléctica en el esfuerzo legitimador de un sistema político sustentado sobre la ley, el orden y la propiedad. Simultáneamente, en los escasos núcleos industriales del país, coincidiendo con el fin del exilio liberal, con las primeras movilizaciones obreras y campesinas y con los ecos revolucionarios de 1830 y 1848, irán alzándose corrientes críticas o radicales de reforma social cuyo mayor valor residirá en su capacidad para anticipar el cambio de protagonistas en la futura lucha contra la desigualdad.

Enviado el (Submission Date): 14/01/2017

Aceptado el (Acceptance Date): 12/03/2017 